\title{
A strategic and data production frameworks for the development of business statistics
}

\author{
Stefano Menghinello ${ }^{\mathrm{a}, *}$, Alison Pritchard $^{\mathrm{b}}$, Daniela Ravindra ${ }^{\mathrm{c}}$, Arturo Blancas $^{\mathrm{d}}$, \\ Gerardo A. Durand Alcantara ${ }^{\mathrm{e}}$, Hank Hermans ${ }^{\mathrm{f}}$ and Saleh Al-Kafri ${ }^{\mathrm{g}}$ \\ ${ }^{a}$ Chair of the United Nations Committee of Experts on Business and Trade Statistics, Director of Data Collection, \\ Italian National Institute for Statistics, Italy \\ ${ }^{\mathrm{b}}$ Leader of the Task Team on Wellbeing and Sustainability, Member of the Board of UNCEBTS, Business Statistics \\ Advancement and Enhancement, Data Collection Transformation, Office for National Statistics, Swyddfa Ystadegau \\ Gwladol, United Kingdom of Great Britain and Northern Ireland \\ ${ }^{\mathrm{c}}$ Leader of the Task Team on Globalization and Digitalization, Member of the Board of UNCEBTS, Director General, \\ Economy-wide Statistics Branch, Directrice Générale, Direction de la Statistique Economique, Statistics \\ Canada/Statistique Canada, Canada \\ ${ }^{\mathrm{d}}$ Leader of the Task Team on Business Dynamics, Business Demography and Entrepreneurship, Member of the Board \\ of UNCEBTS, Director General of Economic Statistics, INEGI, Mexico \\ ${ }^{\mathrm{e}}$ Deputy Director General of Economic Administrative Records, Directorate General of Economic Statistics, INEGI, \\ Mexico \\ ${ }^{\mathrm{f}}$ Leader of the Task Team on Exhaustive Business Registers, Member of the Board of UNCEBTS, Director of \\ Economy, Business and National Accounts, Statistics Netherlands, The Netherlands \\ ${ }^{\mathrm{g}}$ Leader of the Task Team on Capacity Building for Statistical Business Registers, Member of the Board of \\ UNCEBTS, Director General of Economic Statistics, Palestinian Central Bureau of Statistics, Palestine
}

\begin{abstract}
This paper highlights the key characteristics and implications of the strategic and data production frameworks designed and progressively implemented by the United Nations Committee of Experts on Business and Trade Statistics (UNCEBTS) to enhance the relevance, accuracy and coverage of business statistics, according to an internationally comparable, result-oriented and sustainable approach. The strategic framework aims to expand the traditional scope of official business statistics by including all relevant environmental and social related issues. NSOs may achieve relevant improvements by focusing their efforts upon specific global goals consistent with their national ones, and sourcing from knowledge sharing with other countries and international coordination. It also highlights the relevance of an enterprise-centered approach for a better understanding of emerging phenomena by official statisticians, and for priority setting in improving the quality of business statistics. The data production framework is dominated by the crucial role of the Statistical Business Register (SBR) as the backbone of any current and future improvements in the relevance and accuracy of business statistics. Its implications, both in terms of sustainability of production lines, data integration and production of new indicators that exploit the variability dimension of business statistics are further investigated in the paper.
\end{abstract}

Keywords: Business statistics, Statistical Business Registers, globalization, digitalization, maturity model, firms heterogeneity, Wellbeing and Sustainability, new data sources, enterprise, business model

\section{Introduction}

${ }^{*}$ Corresponding author: Stefano Menghinello, Italian National Institute for Statistics, Via Cesare Balbo, 3900184 Rome, Italy. Tel.: +39 3477032 502; E-mail: menghine@ @istat.it.
This paper originates from, and further develops, the ideas included in a technical note submitted to the United Nations Statistical Commission at its Fifty-first 
session in 2020 [1]. The note was prepared by the Bureau of the United Nations Committee of Experts on Business and Trade Statistics (UNCEBTS), which includes the Chair and the task team leaders of the UNCEBTS, Eurostat, OECD and UNSD. The UNCEBTS was established in 2018 in response to the request by the United Nations Statistical Commission [2].

Since its establishment, the Committee has represented a unique global forum for open discussion among official statisticians on the future perspectives of development for business and business-related international trade statistics. The meetings of the Committee have been characterized by a very active and constructive participation of several countries from all around the world, including also international organizations, such as OECD, IMF and Eurostat among others.

Although the activities of the Committee are still ongoing, and some projects are still in an early stage of development, the substantial convergence reached by countries from different regions of the world on "what" and "how" should be done in the future to improve the relevance of business statistics represents by itself a major achievement. This outcome seems worthy of dissemination, even outside the professional community of official statisticians engaged in the design, production and dissemination of official business statistics.

The Strategic Framework for the future development of official business statistics addresses the issue of what NSOs should do to produce high quality and business relevant official statistics in the near future. This is described in Sections 2 and 3. In particular, Section 2 highlights a set of priority areas for official business statistics, as they emanate from the current national and international dialogue on new needs of data users and policymakers. This well-defined list of priorities facilitates the focus of national efforts and international coordination. Section 3 introduces the enterprise-centered approach to business statistics. The enterprise-centered approach responds to the needs to better identify and account for increased heterogeneity in national disseminations of official business statistics that can better meet the needs of the policy and user community of understanding the impact of globalization, digitalization, wellbeing and sustainable development.

This approach is also very useful to set priorities in the quality assessment of business statistics. It is also valuable to better understand the evolution of nowadays businesses. This approach may lead, in perspective, to adopt new classification schemes and, eventually, to evolve the basic statistical units of analysis adopted for the compilation of business statistics. This in order to make business statistics more consistent and relevant with respect to the current evolution of businesses and global production chains in a context of globalization, digitalization and sustainability. Another feature of the UNCEBTS is the priority of not leaving one behind, that means, the Committee seeks the cooperation, exchange of practices and offering guidance to support the development and strengthening of the SBR particularly in developing countries, through a self-assessment by following an SBR maturity model.

The data production framework complements the strategic framework by addressing the issue of how NSOs should produce official business statistics in the near future, by adopting a new cost-efficient and data quality-augmenting production framework. This is illustrated in Sections 4 and 5. Three key elements characterize the new data production framework: the use of the Statistical Business Register (SBR) as the backbone to produce official business statistics, the development of a new set of classification schemes and indicators, and new methods related to microdata linking, and data exchange and sharing. Sections 6 draws the final conclusions.

\section{Broadening the scope of official business statistics and the definition of shared priorities}

The United Nations Committee of Experts on Business and Trade Statistics (UNCEBTS) fully acknowledges the need to expand the traditional scope of official business statistics and business related international trade statistics beyond their traditional borders. New topics to be considered within the extended boundaries of business statistics are, among others, the pervasive impact of digitalization, globalization and sustainability on business organization and performance, the emergence of new business sectors, models and products, the impact of the business sector on social and environmental issues and the blurring between the business and household sectors. ${ }^{1}$ In order to achieve these and other very challenging objectives, a strategic framework is designed and implemented.

The strategic framework consists of three basic elements. Firstly, the set up and maintenance of an appro-

\footnotetext{
${ }^{1}$ For further information on the social and environmental issues addressed by the UNCEBTS, please see the following reports and resolution of the UN General Assembly on Entrepreneurship for Sustainable Development: UN, 2018 https://undocs.org/A/73/258; UN, 2018 https://undocs.org/A/C.2/73/L.35/REV.1; UN, 2019 https:// undocs.org/pdf?symbol=en/A/RES/73/225.
} 
priate global governance model that can actively oversee and support the development of official business statistics by NSOs in terms of identification of possible directions, knowledge sharing based upon national best practices, and internationally harmonized recommendations and guidelines on how to design and implement new official figures. In line with this perspective, and in order to avoid duplicates and leverage other efforts, the UNCEBTS is explicitly designed to work as an "umbrella" under which NSOs and international organizations can openly discuss, evaluate and better coordinate the development of business statistics. In particular, the UNCEBTS facilitates and stimulates the coordination at a global level of medium-long terms programs of development in the areas of business statistics and business related international trade statistics that have a cross-cutting impact with respect to already established international working groups or task forces. Secondly, the identification of priority areas reflects a dual purpose. At the global level, it ensures an appropriate coverage with respect to the broader scope for official business statistics supported by the UNCEBTS At the national level, it enables NSO to obtain tangible results in a reasonable timeframe according to the maturity level of their SBRs, seeking that all can get in the long run a same level of development. Each priority area is set up as the outcome of open discussion within all members of the UNCEBTS. Therefore, it reflects both goals solicited at the global level by international organizations, policy makers, and other stakeholders such as private sector, the media and academia, as well as national specific information concerns and policy needs. Each country member of the UNCEBTS is free to choose and join the work program of the priority area that best match its national information needs and NSO preferences. Every priority area will be periodically reviewed, possibly every three years, by taking into account the evolution over time of users' needs, through user-producer dialogues, such as the international forum already established by UN labelled as Friends of the Chair Group on Economic Statistics.

Thirdly, the program of work of each priority area is set up and periodically overviewed by a task team leader. The task team leader is usually a senior statistical officer from a NSO that has a well-established international reputation in the development of official business statistics, including experimental data, in the priority area of interest. The first goal of each task team is to set up a conceptual scheme to support the development of new statistics or to improve the quality and granularity of already existing ones. This goal is usually achieved by exploiting and interconnecting the work already done by international technical groups and national best practices and filling in all the relevant gaps. The task team then explores all relevant data sources and available methodologies that can support the production of new statistics, as well as strengthening the already existed ones, in line with the characteristics of the data production framework described in the following sections of this paper. In particular, national best practices, including experimental data, are considered as leading examples to further enhance the development of business statistics in the priority area. A list of priority indicators is set up by each task team to ensure the production of new data according to high standard of quality and international comparability, taking into account what users have expressed as major data gaps both at the national and the international level.

Five priority and work support areas were identified by the UNCEBTS during its first meeting held in Mexico City in May, 2018 [3]. All these areas were selected to enhance the relevance, accuracy and coverage of business statistics according to an internationally comparable, result-oriented and sustainable approach for data production. The priority areas on Globalization and digitalization, Wellbeing and sustainability, Business dynamics, demography and entrepreneurship are designed to meet users' needs in terms of better quality and increased data granularity for current statistics, and active engagement in the measurement of new and more complex phenomena. The work support areas on Exhaustive business registers and Capacity building for statistical business registers are mainly focused upon the reinforcement of existing data production infrastructure. More specifically they support the set up of the Statistical Business Register (hereafter SBR) or its evolution toward more advanced and quality-oriented ones. This in order to empower the production of better quality and new business statistics by no leaving one behind and seeking to strengthen less developed statistical infrastructures, particularly those related to the use of business registers for statistical purposes. Figure 1 highlights the central role played by the SBR to ensure the overall coherence and evolution of the priority and support work areas of the UNCEBTS.

The digital transformation is the profound transformation of business and organizational activities, processes, competencies and models to fully leverage the changes and opportunities of a mix of digital technologies and their accelerating impact across society in a strategic, prioritized way. It has contributed a great deal to the globalization of business activities, a process 


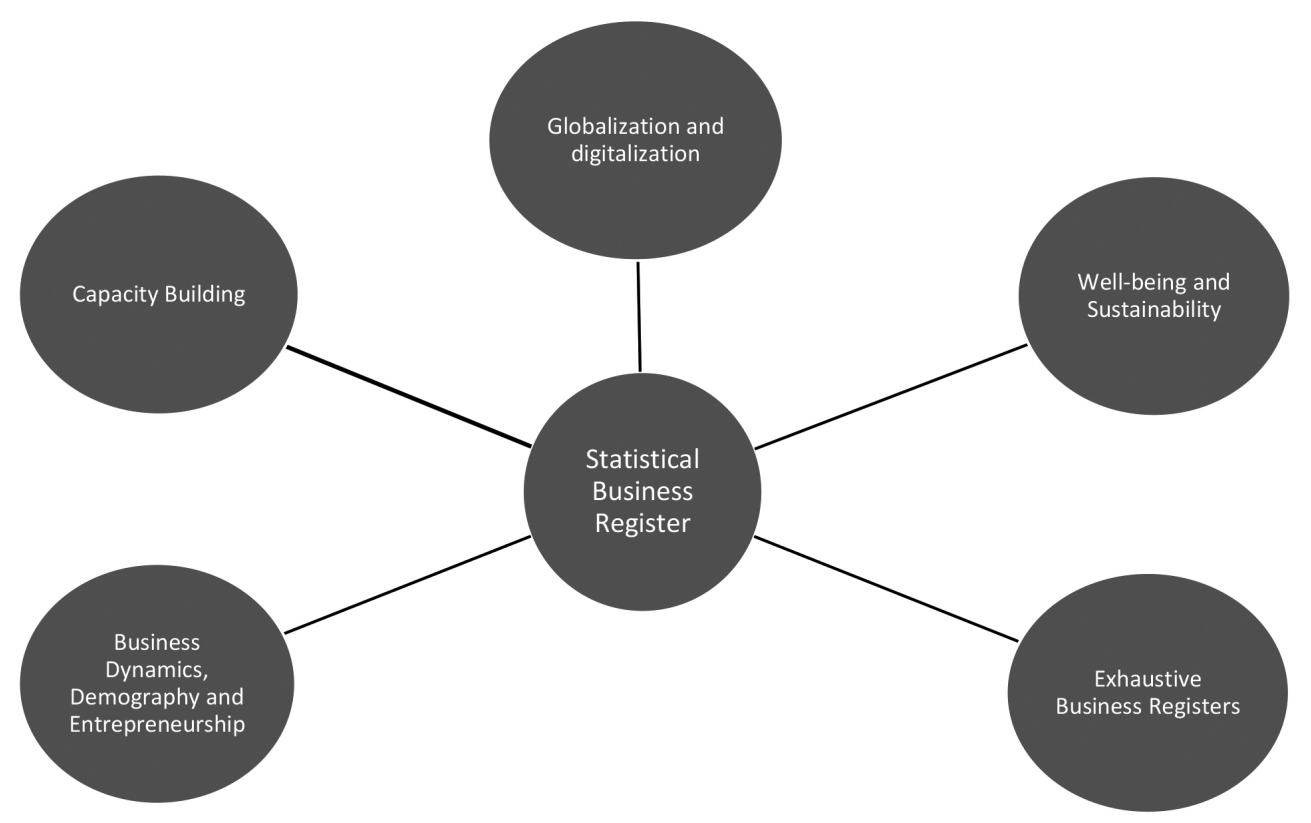

Fig. 1. UNCEBTS priority and support work areas and their link to the SBR. Source: Authors' elaborations.

by which businesses develop international influence or start operating on an international scale.

The priority area focusing on both Globalization and Digitalization acknowledges a converging pattern to define a common and integrated measurement framework in which the role of the multinational enterprise (MNE) is recognized. Traditionally, globalization and digitalization are investigated by analysts and official statisticians as independent themes, whereas the task team would like to explore a more integrated approach of the measurement of globalization and digitalization based on the emerging dominance of global and national business models.

To deal with the challenges presented by digitalization, and in particular to better articulate its impact on the economy, updates across the core statistical information system are required: classifications, definitions, methods of data collection, and data processing. For instance, it is important to have a common understanding of what comprises the digital economy. As digitalization has permeated all aspects of business activity we know that digitally ordered, platform enabled and digitally delivered goods and services fall within the scope, but we must also consider digitally enabled businesses, such as internet intermediaries, e-commerce enterprises and the like. Other challenges also emerge with respect to concepts, and in particular pertaining to the production boundary of GDP, and whether it should be extended to better account for 'data' and the use of data and production, and, also, concerning free services, which are driving a wedge between measures of consumption in the national accounts and notions of material well-being. Digitalization has also enabled the explosion of the gig economy, a sector that has blurred the lines between household and business production.

The priority area on Business Dynamics, Demography and Entrepreneurship emphasizes relevance (for economic analysis and policymaking), measurability and international comparability for a proposed set of internationally agreed business statistics indicators. With the emphasis on the evolution of individual businesses over time, granularity, and distributional information, it aims at exploring the need for introducing appropriate cross-sectional groupings of business units beyond the traditional groupings of size and economic activity. It also evaluates the opportunity to expand current indicators, building upon national best practices, on high-growth firms, births and deaths by extending towards new characteristics. The approach recognizes the scope to identify, and mainstream, new characteristics in SBRs (which can also help generate better stratification variables for business surveys) and also the considerable scope to add these links (and indeed to generate data) through linking across firm-level registers and data sources.

The priority area on Well-being and Sustainability aims to cross-fertilize business statistics with data and users needs coming from other statistical domains. In 
particular, the focus of this priority area is, more than other priority areas, on the information needs set up by the 2030 Sustainable Development Agenda. More specifically, it focuses on the link between business activity and corporate social responsibility and extending the scope of business units to non-profit organizations and the informal sector.

The priority area on Exhaustive Business Registers aims at developing guidance for the SBR to become more inclusive and exhaustive in a rapidly changing economy and to be better tailored to statistical production. Its starting point is to develop a strategic view on the SBR, so that a gap analysis can be performed and guidance can be given for bridging this gap, by taking into account that the interpretation of 'exhaustive' differs amongst countries and is heavily depending on the stage of maturity of the SBR. In order to carefully assess the stage of development of the SBR, it also aims at formulating an internationally-agreed upon maturity model for SBRs across a limited number of components. As it will be clearer from the following sections, the possibility to carefully assess the state of development of a SBR is essential for a NSO to evaluate the scope and data quality returns from using its SBR to expand the coverage of business data or to exploit new data through data linkage techniques. It is also developing the international guidelines for the development of a Global Groups Register. The priority area labelled as Capacity Building on Statistical Business Registers strictly cooperates with the priority area on Exhaustive Business Registers to develop international guidelines for the maintenance, update and upgrade of SBRs, especially from the perspective of developing countries.

\section{The adoption of an enterprise-centered approach for official business statistics}

Real businesses today navigate a complex and fastevolving economic and regulatory environment in which they continuously arrange and re-arrange legal structures through core and outsourced business functions facilitated by an ever-changing technological production environment. This business environment is increasingly dominated by international trade in goods and services and cross-border legal ownership relationships between firms, where underlying transactions are often identifiable only in relation to the enterprise. Indeed, in today's global and digital economy, business operations of production, investment, ownership and finance require an integrated approach at the enterprise level to optimize the domestic and international business operations.

The set of statistical units, variable definitions, classification schemes and related guidelines currently used by NSOs for the compilation of official business statistics is evolving to catch up with these radical changes. However, some relevant achievements seem to be domain specific, indeed they typically occur in sectors of official business statistics more exposed to those changes, such as globalization and digitalization related statistics. In addition, major gaps still persist on how to correctly classify specific operations made by multinational enterprises, whether or not to include some emerging activities in the business sector, and how to consider new business models that are apparently neither profit seeking nor market oriented.

The enterprise-centered approach aims at overcoming some of these limitations by introducing a broader and more consistent perspective on the measurement and analysis of the structure, behavior and economic performance of businesses. Indeed, the highly fragmented nature of business statistics based upon large scale independent sample surveys and a relatively wide range of concepts, definitions and classifications, calls for a unifying approach it before proceeding to define a feasible and common data production framework.

The enterprise-centered approach, originally introduced by UN (2019) in the context of Global Value Chains analysis and measurement [4], is reconsidered and expanded here to streamline the classification, integration and production of new statistics on the business sector. The adoption of this approach stems from the fact that the enterprise is considered the economic agent with the capacity to decide on all its business activities, which also means that it is often the most common unit of data collection or around which different data sets can be linked. The adoption of an enterprise-centered approach to business statistics does not imply that other statistical units are less relevant. Rather, the choice of the enterprise as the main analytical unit allows for the coherent measurement of the evolution and behavior of business activity. In addition, the choice of the enterprise as the analytical unit does not mean that the observation unit also has to be an enterprise, however, it does require that each of those units can be aggregated to provide a view of the enterprise. As such, the SBR should contain the appropriate characteristics of the enterprise and the relationships between the different statistical units to guide the choice of the observation and reporting units. 
The enterprise-centered approach addresses the following methodological and conceptual aspects:

- Data integration within the business sector: it serves as the reference unit for data integration processes and for the assessment of data quality across different statistical domains related to production, employment, trade, investment, finance and ownership. Sound data linking processes between two or more data sources should consider the enterprise as the reference unit for data integration, using a core set of characteristics of the enterprise in the SBR. This core set of characteristics of enterprises is referred to as the "spine" of the SBR. In addition, the inconsistency between variables related to different data sources after data integration (e.g., the link between business characteristics, the export values and product details) is usually resolved when managed at the enterprise level.

- Setting priorities: it allows for the identification of enterprises with the highest impact on national business-related statistics in order to prioritize their data collection and quality control. Even in developing countries, while the availability of a limited number of units in the SBR can result in partial coverage of the economy, the quality of the data collected can still be high for national business-related statistics if the quality and coverage of leading firms resident in the country are assured by automatic or manual quality checks.

- Linking relationships between units of the enterprise: it describes the link between statistical units of the enterprise and provides the key to scale up or scale down business-related information according to a well-defined set of statistical units, such as establishment, enterprise, enterprise group, and MNE. In particular, the inclusion in the SBR and data integration processes of other statistical units, such as local units (plants) or enterprise groups, shall be carried out by keeping both an horizontal (across variables) and vertical (across units) coherence from micro data up to aggregated figures in order to guarantee the production of high-quality and fully consistent business statistics.

- Ensuring data quality, consistency and coherence: it provides the possibility to more easily detect and correct major bias in the data by comparing different data sources related to information on an enterprise's business operations related to production, trade, employment, finance and ownership. It facilitates the integration of information that is normally collected at the enterprise level (such as R\&D expenditure, ownership, innovation, and balance sheets) with production, income and expenditure data, which is currently collected at the establishment level.

- Facilitating data exchange and sharing arrangements: it provides a better opportunity for NSOs and international organizations to collect, share and analyze enterprise-level information to ensure its global coherence.

- Monitoring of legal structures of enterprises: it allows for a better monitoring of relatively rapidly changing legal structures of enterprises, as well as their evolution.

- Proving a feasible and fully consistent data production framework to fully exploit the micro-data informative potential of SBR integrated data for the dissemination of new outputs.

The adoption of an enterprise-centered approach can be also highly effective to capture how current businesses are evolving with respect to conventional wisdom on enterprise structure and performance. An enterprise is usually considered as an economic agent operating as a single legal unit, exclusively oriented to making profit, carrying out only domestic and local business operations, also characterized by a high degree of homogeneity with respect to outputs, and the use of domestic and industry-specific inputs and technology. All these characteristics should be reconsidered in the light of the ongoing work done by priority and work support areas of the UNCEBTS as illustrated in Fig. 2.

The priority area on Globalization and digitalization warrants an evaluation of the traditional view of the enterprise to take into account a wide range of issues generated by the interplay of the globalization and digitalization dimensions. These includes the international sourcing of business operations through firm networks in global value chains, the development of new business models, and the use of cross-cutting technologies in different industries (not only for large complex enterprises, but also for small and medium-sized enterprises (SMEs)). The priority area on Business dynamics, demography and entrepreneurship reviews the relevance of traditional economic classification schemes, which are based on industry, enterprise size and territorial location, in explaining differences across firms in birth, death and high-growth rates. This priority area considers new core concepts for better understanding entrepreneurship, business demography and business dynamics, and for presenting a set of indicators that can be used to support the analysis and implementation of 


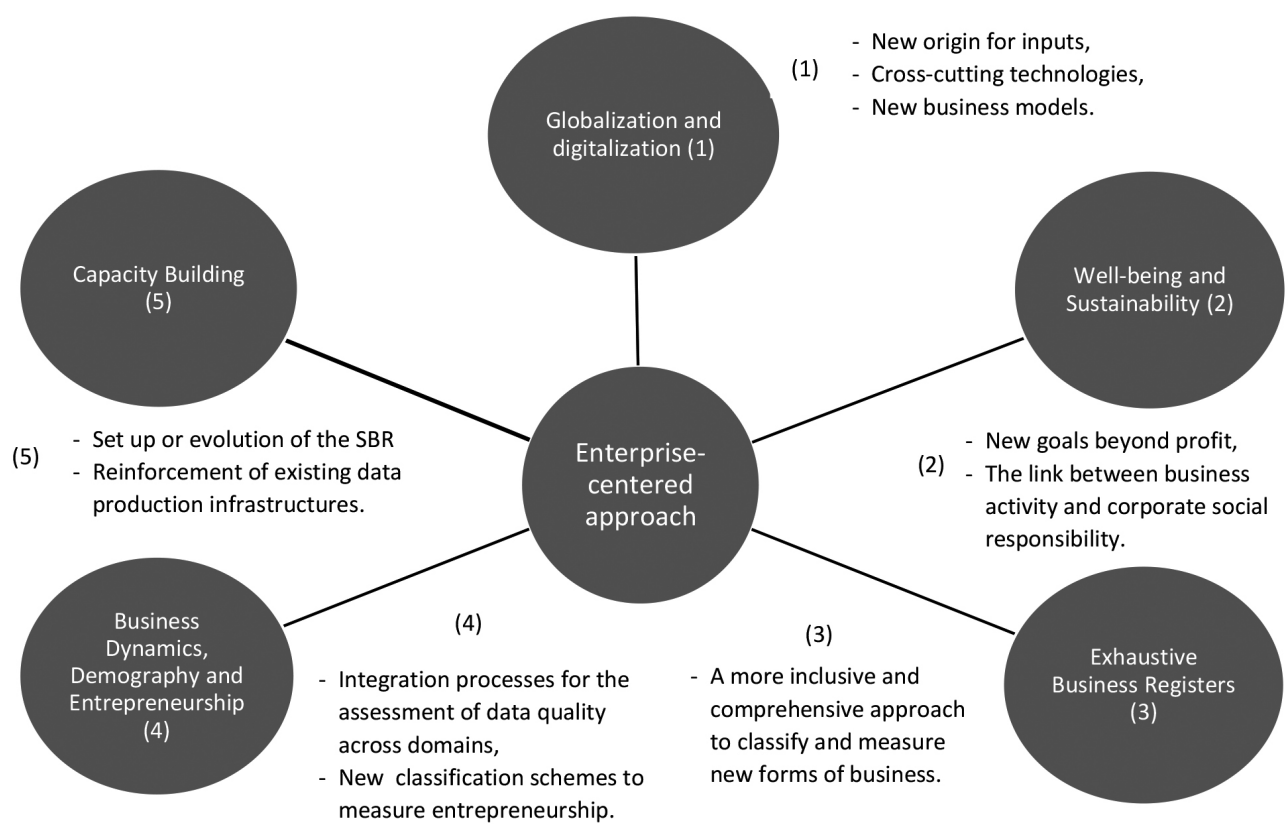

Fig. 2. UNCEBTS priority and support work areas and their impact on the enterprise-centered approach. Source: Authors' elaborations.

public policies that encourage entrepreneurial activity. The priority area on Well-being and sustainability expands the motives of business enterprises beyond the exclusive pursuit of profit to also consider social responsibility and environmental sustainability. The work support area on Exhaustive Business Registers explores the boundaries of market-oriented business sectors and aims to expand the scope of SBRs to new forms of business activity oriented to non-profit activities and the informal economy.

\section{The SBR as the core of the new data production framework for official business statistics}

The current framework adopted by National Statistical Offices (NSOs) for the production and dissemination of official business statistics has been largely designed to meet a relatively narrow set of user needs, generally related to industry-level business characteristics, such as employment, turnover, value added, labor costs, fixed investment and related productivity and profitability indicators. Additional indicators, such as research and development (R\&D) expenditure, technological innovation and ICT usage, mainly focus on technology as a part of the enterprise or the industry's production function. Indeed, important considerations, such as data quality and timely availability of short-term indicators, also play a crucial role in the production of official business statistics.

Moreover, the possibility of those indicators to cover new dimensions of the business economy is constrained by the existing model of data production for business statistics. The new dimensions include, for instance, the breakdown of official business statistics indicators between exporting and not exporting enterprises in manufacturing, increasing granularity in data dissemination beyond the standard estimation domains or the exploitation of new information on firms' heterogeneity in a given sector or size class. More specifically, the current methodological approach does not allow for flexibility given the use of costly surveys and the rigidities in the statistical production process as well as the constraints imposed by random sampling design.

Last but not least, most users now seek statistics on business activity that are flexible with respect to their specific needs and multi-dimensional in nature, such as measures of the social and environmental impacts from business activity, to better address the complexity of developed and developing economies. This also calls for an increasing coverage in the classification and measurement of business statistics to include units from the non-profit and informal sectors and measures of the impact of new technology on entrepreneurial activities and self-employment.

The achievement of these goals requires not only a reorientation of the outputs realized by NSOs but also a 
radical reorganization on how the model of statistical production adopted by NSOs shall be reorganized in order to fully support more substantial and persistent results.

The SBR already plays a crucial role in official statistics. It provides the frame to correctly identify the target population for business surveys, to randomly select the sample of units under investigation, and to grossup the sample of survey respondents. However, with a few limited exceptions, such as in the case of business demography indicators, NSOs have usually given little attention to the SBR as a direct source of information to produce business statistics. Indeed, the SBR contains some highly desirable characteristics for data dissemination, such as its exhaustive nature, and the high level of coherence of information on business units. Because SBRs are not constrained to survey-specific sample designs, the information included therein can be disseminated with a high degree of granularity (such as breakdowns by industry, location and enterprise size). Official statistics produced following this SBR approach can be easily reclassified ex-post according to non-standard classification schemes, and consistently integrated with other data sources. In addition, the set-up and maintenance of SBRs usually rely upon administrative or fiscal data sources, which limits the response burden and lowers the data collection costs as compared to survey collection.

As a result, the SBR can play a pivotal role in the process of data integration with different and multiple data sources by generating new information with the desirable characteristics described above [5]. Appropriate micro-data linking methodologies based upon unique identifiers could be applied to produce consistent information scalable from micro to aggregated figures [6]. The Linked Employer Employee Data (LEED) approach, in which business micro data is being linked to jobs and other social statistics, is an example of data linking between statistical business and household units.

However, the ability of the SBR to easily generate consistent and extended data sets through data linking crucially relies upon successful matching of micro data sources that hold similar characteristics. An example is the linking of SBRS with census-like administrative data sources that have been harmonized for statistical definitions of the statistical units and variables. In addition, the SBR can be linked with other company lists or registers, such as the list of exporting and importing enterprises from customs records as demonstrated by the production of TEC (Trade by Enterprise Characteristics statistics) in many countries.
Innovative approached can be developed to fully exploit SBRs to enhance data integration, using a spine model consisting of a core set of business characteristics [7]. The integration of business registers according to the spine model will also be explored for purposes of the Global Groups Register of the largest MNEs presently being developed by UNSD, building on the experience of the EuroGroups Register operated by Eurostat.

In order to improve the quality and granularity of business statistics, and to understand the increasingly complex role of businesses and MNEs in global production and employment, it is necessary to develop more efficient ways to collect, integrate and produce business statistics. Such strategies include microdata linking (MDL); profiling large and complex MNEs; and data sharing or data exchange. MDL, or the combining of micro-data on entities, such as enterprises, jobs and persons, not only reduces respondent burden, but also supports analysis of both firm and employee characteristics and can help in answering questions on job dynamics, income and welfare.

Furthermore, to ensure meaningful and correct measurement of global production and trade, many statistical offices are considering how to improve data specifically on large and complex MNEs. At the national level, Large Case Units (LCUs) are increasingly being established in NSOs to improve the quality, consistency and coherency of data on MNEs by coordinating data collection and compilation, ensuring data consistency across all data sources, and building client relationships with the respondent MNEs. For producing statistical data related to MNEs the use of new and innovative data sources for reducing statistical burden and cost to NSOs including direct data collection from MNEs, an improved legal framework and more intensive use of administrative data should be supported.

Bilateral exchange of business micro-data between national statistical offices and possibly with other producers of official statistics would be another way forward in improving the understanding of business dynamics and the operations of MNEs at the global level. However, it is widely known that data sharing of microdata at the international level has proven to be limited due to strict privacy and confidentiality laws. While there are ongoing initiatives to make progress in addressing data sharing issues across countries, such as the G-20 Data Gap Initiative (DGI) and forthcoming ECE Guide to Sharing Economic Data, it is well understood that this is an area that is still being developed. Most business statistics-related projects to com- 
pile internationally comparable statistics to date have utilized "coordinated MDL" or "distributed microdata research", which requires central coordination of the database construction, analysis and publication, respecting subsidiarity and national legislation.

One possible way to address the legal obstacles associated with data exchange is to help countries draft legislation that amend the treatment of data confidentiality. For example, it would be useful to consider an exemption to data confidentiality to allow exchange of firm-level data that are already made publicly available by the respondent itself, perhaps in published annual reports or filings with financial regulators, if the data meet the statistical definitions. These public data could then also be exchanged freely among NSOs and/or consolidated by international and regional agencies. This would be a critical step towards assuring the overall quality of the macroeconomic aggregates and business statistics produced by a country at national and subnational/regional level.

Another topic that needs to be further explored in the next few years concerns the link between new data sources, including big data, and the SBR. The relevance of new data sources to expand the impact of official statistics on the economy and the society is highlighted by a paper included in this Special Issue of the Journal of the IAOS. Indeed, in a new and continuously expanding business data eco-system, the SBR will reinforce its role of backbone of not only official business statistics but also for new data sources. In particular, the SBR can provide the benchmark to assess the degree of under and over coverage as well as the correct classification of all the target populations included in the business sector of the national economy against new data sources that usually incorporate an unstable and potentially biased set of business information [8]. Additionally, the use information of non-traditional sources for statistical purposes displays other challenges to be further addressed such as some confidentiality issues, the quality and validation of new data, the availability, the data governance, and so on.

However, the possibility to fully exploit the pivotal role of the SBR for the production of new business statistics or for improving the quality of current business statistics crucially depends on its stage of development. Indeed, a SBR in preliminary or early stages of development is very likely to generate inconsistent results if integrated with multiple data sources with no additional data quality and data integration controls. Therefore, the maturity stage of a SBS should be carefully assessed before planning its use for the statistical production of complex and innovative outputs. In order to address this very relevant issue, the task teams of the UNCEBTS more directly engaged in designing and assessing the role of the SBS as the core of the new data production framework have proposed a preliminary approach labelled as SBS maturity model.

The SBS maturity model is a tool to assess the stage of implementation of SBR against a set of six elements (called 'dimensions') that characterize SBRs. For each dimension, four different stages of development are considered: preliminary, early, mature and advanced.

The first dimension is the legal framework. It refers to the legal and institutional framework relevant for SBR. Particularly relevant for the SBR is the existence of laws to access administrative sources and the existence of an institutional framework for SBRs. The stages of development of this dimension can be organized from "No specific law to guarantee access to admin sources" to "Laws are in place to guarantee access to admin sources and use of admin data for SBRS".

The second dimension is represented by the main types of data sources that are used as inputs in the set up and maintenance of the SBR, such as administrative data, economic censuses, economic surveys, SBR quality surveys, other private sources. The third dimension concerns the maintenance/update of the SBR. In particular, this dimension deals with the frequency of update (with economic census every 5 years, automatically with administrative data sources, etc.) and the availability of unique identifiers.

The four dimension is the coverage of the units in the SBR. They can be described in terms of the institutional sectors of the units, the size of the units and the variables included in the SBR for each unit. Coverage could also be seen as an outcome of the maintenance procedures and availability of sources. This dimension is heavily related to other aspects. The fifth dimension concerns how the SBR is currently used by the NSO for methodological or business data production purposes. Different uses include as a frame for surveys, to produce SBR-based statistics, to realize longitudinal studies, to participate in international data exchange, to be directly exploited for data dissemination.

The six dimension deals with the IT environment that is supporting the set up and maintenance of the SBR. Different situations can be distinguished, such as no database in place, database in place, automated live updates with administrative data sources, relationships with other systems and environments, integration with complex information eco-system.

The maturity model can be used for different purposes. Self-assessment tool for countries to have a bet- 
ter understanding of where they are with respect to each dimension of the maturity model. This in turn will help countries to develop a plan for improving the SBR based on a cost benefit analysis. As a monitoring tool for the improvement of the SBR based on a standard set of criteria (e.g. dimensions and stages of development for reach dimension). As a support tool for a global assessment of the stage of implementation of SBR in countries. This in turn will help international and regional organizations to develop and tailor capacity development programs to countries' needs.

\section{The need of new classifications and indicators for official business statistics}

As already highlighted in the previous sections, the increasing heterogeneity in the economic structure and economic performance of businesses may cause a loss of relevance for business statistics currently produced by NSOs. This is motivated by two different but indeed deeply interconnected issues. Firstly, the loss of relevance of standard official classifications in explaining a significant share of firm level variability and the inadequacy of standard indicators based upon official statistics in capturing the complexity of nowadays economic reality.

The capability of standard classification schemes to explain firm-level variability based upon basic business characteristics (i.e., industry, enterprise size class and location) has sharply declined in connection to the increased relevance of firm specific assets in explaining the heterogeneity in both level and growth rate of productivity, profitability and new job creation. Firm specific assets encompass technological, commercial, managerial or human capital features that a company may hold independently from its location, size class and industry. New classification schemes should reflect business profiles - such as export activities, provision of services, internationalization processes or new technology adoption (e.g., patents or digital profile) because these latter features have been proven by the academic literature to explain a larger share of firm-level heterogeneity in productivity and profitability as compared to traditional classification variables. All these new statistical or analytical classifications should be integrated in the national SBR in order to allow the production by NSOs of new and fully consistent figures, also controlling for indirect confidentiality problems where relevant.

The relevance of data on the heterogeneity of firms' behavior and business performance to better inform pol- icy makers and the business community on the evolution of the business sector is well understood by academic literature and policy making. The growing importance of the empirical literature based on the econometric modelling of firm level data, also including the use of enterprise level samples from official surveys carried out by NSOs, clearly supports the relevance of this kind of information for research and policy making.

Despite the remarkable importance of this kind of data, standard indicators produced by NSOs are essentially calculated as total or mean-based values (e.g., total or average labor costs, total or average productivity, total and average profitability) of the target business population. The main rationale for that essentially reflects methodological constraints in the current model of data production. Indeed, official surveys carried out by NSOs adopt much larger samples and more complex sampling design as compared to surveys carried out by other public or private entities, mainly researchoriented ones. However, the information that can be sourced from this kind of survey is limited both in terms of data granularity and possibility to fully exploit the heterogeneity of firms' performance.

The adoption of a production framework based upon the SBR substantially changes this scenario. Indeed, the presence of the full set of relevant variables for all the statistical units included in the SBR, obtained by integrating the SBR with other census-like statistical or administrative data sources, supports the production of a new and very informative class of indicators, labelled here variability-based indicators. Variability-based indicators may assume different analytical formulations, but they essentially measure firm level distribution characteristics as distance from mean/median/central values. This class of new indicators is very informative in measuring, for instance, the degree of heterogeneity in economic performance of businesses within the same industry, size class o region (intra-group firm level variability). Indeed, standard business statistics only allow comparing the heterogeneity in (group means based) economic performance of firms across industries, size classes and regions (between-group firm level variability).

The implication of these new indicators to enrich evidence-informed policy making is self-evident. For instance, let's assume that we already know from official statistics that exists a limited gap in the level of productivity across two countries for a specific target population of enterprises identified by a given industry and size class. Variability-based indicators calculated for firm level productivity with respect to the same tar- 
get population in the two countries can be informative of the fact that the country that shows the lower value of firm-level variability exhibits more similar patterns of productivity across firms, while the country with an higher value of firm-level variability in productivity level may have a more polarized business community (in which there are potentially stronger winners but also firms suffering from severe problems).

Even more interesting considerations apply if one considers the evolution over time of firm-level productivity. Productivity stagnation (i.e., no relevant changes over time for the mean values of productivity level for a given country, sector, region or size class) can hide either converging patterns of firm level productivity to the mean value of firms' productivity distribution or a strong increase in their variability with no impact on mean productivity level. In this latter case, bestperforming firms are becoming more competitive, but their impact on industry and country mean productivity is cancelled out by the poorer performance of other businesses that are struggling even more to survive. This distinction is crucial for policy makers in order to set up appropriate policy measures to boost productivity but unfortunately, it cannot be assessed by using standard official business statistics data. Therefore variabilitybased indicators need to be developed to reduce this information gap.

As a result, the SBR approach allows complementing traditional indicators based upon standard figures from business statistics with a new class of indicators that can exploit information on firm level variability. It is then possible to highlight a more complex and complete picture of the evolution of the business sector of the economy. It is important to highlight that only NSOs that have already set up and maintained a SBR fully integrated with statistical and administrative data on company financial statements, are in the position to immediately adopt analytical classifications and to produce the new class of variability-based indicators. For other countries, the adoption of new classification schemes and the production of this new class of indicators can be implemented only in the medium terms based upon the maturity level of their SBR or the adoption of alternative methodological solutions.

\section{Conclusions}

The guidelines proposed by the United Nations Committee of Experts on Business and Trade Statistics and described in this paper to enhance the future develop- ment of business statistics are based upon two different but very closely related frameworks. The strategic and data production frameworks address, respectively, the issues of "what" and "how" NSOs should do to remain relevant in the business sector in a world of fast and radical changes.

The strategic framework starts from a critical assessment of what is needed today in terms of global governance, priority setting, and coordination mechanism to ensure the production of new indicators by NSO. It aims at supporting NSOs to improving the quality of existing business data or to develop new business data and indicators in a reasonably short timeframe in order to improve the readiness of official statistics, both a the national and international level, to cope with increasingly complex and fast evolving users' needs. The answers that genuinely emerge from the technical discussion among all countries concern both the need to broaden the scope of the business statistics domain to include new but intrinsically related social and environmental aspects and relevance of international coordination to facilitate the production of new statistics by clustering the activities around specific priority areas. Each NSO is then free to join the project of foremost interest for its country, and can benefits from other countries' best practices and international standards and active guidance. The alignment between national, regional and global priorities can ensure that progress is made faster by NSOs, which have to face increasing financial constraints and to reconcile global projects and national information needs.

The objective of each priority area is to improve the relevance, granularity and consistency of business statistics using an enterprise centered approach. At an early stage of development, the work done by each priority area concentrates on the fine tuning of concepts and definitions that are designed to capture new and complex economic phenomena according to the high quality standard requested by official statistics. Then a list of priority indicators to measure these phenomena is set up and connected to information already available in the SBR or that can be obtained by enriching the SBR with additional information through data linking techniques. In a more advanced phase, each global priority area will encourage the real production of priority indicators based upon experimental statistics and NSOs best practices. After a careful evaluation of the conceptual work, the methodological approach, and the empirical results, the production of priority indicators will be suggested to all NSO as standard statistical production to improve their impact on new user's needs. 
The introduction of an enterprise-centered approach ensures that all the activities carried out by NSOs will converge toward a unified framework that paves the way to the introduction of the SBR as the reference statistical production model to achieve substantial and persistent results in the development of business statistics. In addition, this approach will lead in the mediumlong terms towards a broader and more business relevant view on the basic characteristics that can be useful to better identify, classify and measure nowadays businesses for statistical purposes. Nevertheless, the enterprise-centered approach may not be sufficient to cover all social and environmental dimensions related to business statistics, the UNCEBTS will evaluate in the future the possibility to introduce a more holistic approach.

The data production framework clearly highlights that the SBR represents for every NSO the backbone of any reliable and sustainable data production system for business statistics aiming at improving the quality and granularity of existing data or to develop new data and indicators. ${ }^{2}$ The maturity level of the SBR set up and maintained by each NSO should be carefully assessed in order to successfully exploit its informative potential and to design a sustainable plan for its further upgrading. The adoption of advance techniques of data linkage and enterprise profiling, together with the active engagement of NSO in international project of global interconnectivity across statistical business registers, can substantially reinforce the consistency and resilience of national based SBR as pivotal element of any high quality statistical production system finalized to the production of new and old business statistics.

The availability of more granular and consistent information, the flexibility of statistical output with respect to both standard and analytical classifications. And the development of a new class of variability-based indicators, are the key advantages that a production framework rooted in the SBR can offer to data users. Finally, the adoption of an internationally coordinated approach for the development of business statistics, based upon globally interconnected priority areas will provide direction and active support to NSOs willing to be engaged in the development of new business statistics or to persistently improve the quality of existing ones following a consistent, stable and sustainable approach grounded in the national SBR.

\footnotetext{
${ }^{2}$ This is in case the SBR available, if not the establishment census will be used instead as starting point to adopt a SBR approach in the production of business statistics.
}

At the time of writing this paper, the global pandemic labelled as COVID-19 has severely hit most of the countries in the world. Several NSOs have already experienced major problems of delay or even discontinuity in the production and dissemination of official figures, including business statistics, for major failures in data collection and other statistical production phases. There is also a growing consensus on the fact that the way private businesses or government activities were organized and performed before COVID-19, including the production of official statistics, will be quite different in the near future.

The scientific and professional value of a paper aiming at identifying the future avenues for the development of business statistics and the related data production requirements based upon activities carried out before COVID-19 may be questioned. However, the direct experience of some NSOs heavily affected the global pandemic in ensuring the continuity, increasing the relevance, of business statistics seems to support rather than discourage the strategic and production frameworks introduced in this paper. In particular, these countries have coped with the disruptive impact of Covid-19 on their statistical production systems by further exploiting the pivotal role of their SBR for both data integration with new data sources and the assessment of the loss of information in direct reporting and administrative data sources. Indeed, the need of NSOs to develop more sustainable, resilient and flexible statistical production systems induced by COVID-19 will most likely accelerate the evolution of business statistics hopefully along the key lines described in this paper.

\section{Acknowledgments}

We would like to thank the two anonymous referees and the editorial team of this special issue of the IAOS Journal. We also acknowledge the valuable and precious contribution provided, directly or indirectly, by colleagues from UNSD, OECD, Eurostat, individually and as members of the Board of the United Nations Committee of Experts on Business and Trade Statistics.

\section{References}

[1] Strategic View on Business Statistics, document presented at the United Nations Statistical Commission at its fifty-first session in 2020 and available at https://unstats.un.org/unsd/statcom/51stsession/documents/BG-Item3e-Strategic-View-on-BusinesStatistics-E.pdf. 
[2] Report of the Statistical Commission on the forty-eighth session (2017) https://undocs.org/E/2017/24.

[3] UN (2018) Summary report of the First Meeting of the Committee of Experts on Business Statistics. Available at https:// unstats.un.org/unsd/trade/events/2018/mexico/Summary\%20 Report\%20of\%20the\%20UN\%20Committee_Mexico\%20mee ting_final.pdf.

[4] UN (2019) Accounting for Global Value Chains: GVC Satellite Accounts and Integrated Business Statistics, Available at https:// unstats.un.org/unsd/business-stat/Assets/Documents/GVC.

[5] Wallgren, A. and Wallgren, B. (2013) "Register - based Statistics: Administrative Data for Statistical Purposes" John Wiley \& Sons, Ltd, Chichester, UK (second edition).
[6] Luzi, O. and Monducci, R. (2016) The new statistical register "Frame SBS": Overview and perspectives, Rivista di Statistica Ufficiale, ISTAT - Italian National Institute of Statistics (Rome, ITALY), 18(1), 5-14, web reference http://www.istat. it/it/files/2016/11/1_luzi.pdf.

[7] Australian Bureau of Statistics (2019) "Towards a more flexible ABS Business Register" available at https://unstats.un.org/ capacity-building/Meetings/CEBTS/UNCEBTS_5a_ABS_ Flexible_BR.pdf.

[8] Menghinello, S., Laureti, T. and Faramondi, A. (2020) "The future role of official statistics in the business data arena", Vol 36/2. Statistical Journal of the International Association for Official Statistics. 